\title{
Effects of nettle slurry (Urtica dioica L.) used as foliar fertilizer on potato (Solanum tuberosum L.) yield and plant growth
}

\author{
Alfonso Garmendia ${ }^{1}$, María Dolores Raigón ${ }^{2}$, Olmo Marques ${ }^{3}$, María Ferriol $^{1}$, Jorge Royo ${ }^{3}$, Hugo Merle \\ Corresp. 3 \\ 1 Instituto Agroforestal Mediterráneo, Universitat Politècnica de València, Valencia, Spain \\ 2 Instituto Universitario de Conservación y Mejora de la Agrodiversidad Valenciana, Universitat Politècnica de València, Valencia, Spain \\ 3 Departamento de Ecosistemas Agroforestales, Universitat Politècnica de València, València, Spain \\ Corresponding Author: Hugo Merle \\ Email address: humerfa@upvnet.upv.es
}

Organic agriculture is becoming increasingly important, and many natural products are now available for organic farmers to manage and improve their crops. Several ethnobotanical studies have indicated that the use of nettle slurry as fertilizer in organic farming for horticultural crops is spreading. Sometimes, however, the consequences of using these natural products have been poorly evaluated, and there is very little scientific evidence for the effects of using these slurries. In this study, we aimed to analyze the possible effect of nettle slurry on potato yields produced by organic farming. To achieve this main objective, we assessed the effect of nettle slurry on potato yields, plant size and growth parameters, chlorophyll content, and the presence of pests and diseases. Different slurry doses were assessed in 36 plots and nine variables were measured during the crop cycle. Under these field experimental conditions, nettle slurry (including one treatment with Urtica in combination with Equisetum) had no significant effects on yield, chlorophyll content, or the presence of pests and diseases in organic potato crops. The highest chlorophyll content was found in the double dose treatment, but the difference was not significant. This result, together with a small improvement in plant height with the double dose treatment, might indicate very slight crop enhancement which, under our experimental conditions, was not enough to improve yield. The Urtica and Equisetum slurry chemical analyses showed very low levels of nitrogen, phosphorus and potassium. 


\title{
Effects of nettle slurry (Urtica dioica L.) used as foliar fertilizer on potato (Solanum tuberosum L.) yield and plant growth.
}

\author{
Garmendia $\mathrm{A}^{1}$, Raigón $\mathrm{MD}^{2}$, Marques $\mathrm{O}^{3}$, Ferriol $\mathrm{M}^{1}$, Royo $\mathrm{J}^{3}$, Merle $\mathrm{H}^{3 *}$ \\ ${ }^{1}$ Instituto Agroforestal Mediterráneo, Universitat Politècnica de València, Valencia, Spain. \\ ${ }^{2}$ Instituto Universitario de Conservación y Mejora de la Agrodiversidad Valenciana, Universitat \\ Politècnica de València, Valencia, Spain \\ ${ }^{3}$ Departamento de Ecosistemas Agroforestales, Universitat Politècnica de València, Valencia, \\ Spain.

\section{*humerfa@upvnet.upv.es}

\begin{abstract}
Organic agriculture is becoming increasingly important, and many natural products are now available for organic farmers to manage and improve their crops. Several ethnobotanical studies have indicated that the use of nettle slurry as fertilizer in organic farming for horticultural crops is spreading. Sometimes, however, the consequences of using these natural products have been poorly evaluated, and there is very little scientific evidence for the effects of using these slurries. In this study, we aimed to analyze the possible effect of nettle slurry on potato yields produced by organic farming. To achieve this main objective, we assessed the effect of nettle slurry on potato yields, plant size and growth parameters, chlorophyll content, and the presence of pests and diseases. Different slurry doses were assessed in 36 plots and nine variables were measured during the crop cycle. Under these field experimental conditions, nettle slurry (including one treatment with Urtica in combination with Equisetum) had no significant effects on yield, chlorophyll content, or the presence of pests and diseases in organic potato crops. The highest chlorophyll content was found in the double dose treatment, but the difference was not significant. This result, together with a small improvement in plant height with the double dose treatment, might indicate very slight crop enhancement which, under our experimental conditions, was not enough to improve yield. The Urtica and Equisetum slurry chemical analyses showed very low levels of nitrogen, phosphorus and potassium.
\end{abstract}

\section{Introduction}

The latest survey on certified organic agriculture worldwide has shown that 50.9 million hectares of agricultural land were managed organically at the end of 2015 (Lernoud \& Willer, 2017). Allimportant indicators have been increasing in the last decades: area, producers and retail sales (Lernoud \& Willer, 2017). This significant growth in organic farming is not only a matter of a marginal agricultural change, but also represents the implementation of major changes in society, and their relation with agriculture (Michelsen, 2001; Lobley, Butler \& Reed, 2009; Reganold \& Wachter, 2016). Organic food consumption is associated with health beliefs and subjective wellbeing, which involves higher market values and demand (Apaolaza et al., 2018). Recent studies highlight that organic food is related with important benefits for human and environmental health 
(Kahl \& Rembiallkowska, 2014; Gomiero, 2017). Moreover, in the next few years, agriculture will be pushed to become more sustainable as a global response to climate change.

Increasingly more natural products are available for organic farmers to manage and improve their crops (Benfatto et al., 2015). Many agrochemical companies are including organic fertilizers, natural herbicides or bio-based liquid formulations to control pests, in the products they offer. Some of these companies merely focus on natural products for organic farmers. However, the consequences of using these natural products for crop yields and other agro-ecosystem services have sometimes been poorly evaluated (Gagic et al., 2017).

Several ethnobotanical studies have indicated that the use of nettle (Urtica dioica L.) slurry as fertilizer in organic farming for horticultural crops is spreading in Spain (Latorre JA, 2008; Benítez Cruz G, 2009). Small farmers can produce their own slurry, but most professional organic farmers usually buy the commercial product (field surveys). Companies must follow EC regulation No. $1107 / 2009$ to obtain active substances. The purpose of this regulation is to ensure a high level of protection of both humans and the environment and, at the same time, to safeguard the competitiveness of the agriculture community (OJ, 2009). Many trading houses from different countries commercialize nettle slurry (e.g.: I.L.A.G.A., ARIES biogarten, General Organics, Trabe S.A., Asocoa, AgroBeta, MGI Developpement, etc.). Thus nettle slurry is commonly used in organic agriculture and has a growing economic impact. Labeled general effects include leaf fertilizer, growth stimulator, ferric chlorosis control, pest and disease prevention, and insect repellents. Trading houses recommend three applications at 10\% v/v and $300 \mathrm{l} / \mathrm{ha}$ over the crop cycle.

The chemical composition of nettle plants has been widely studied for medical purposes (Zekovic et al., 2017). Its antioxidant capacity, therapeutic effect or immunological responses have often been recorded (Buenz et al., 2017; Branisa et al., 2017; Saeidi Asl et al., 2017). The potential industrial uses of stinging nettle were summarized by Di Virgilio et al (2015). They concluded that nettle have promising application in the food/feed, medicinal and cosmetic sectors (Di Virgilio et al., 2015). Surprisingly very few studies have centered on the agronomic use of nettle slurry as fertilizer, the chemical composition of fermented slurry, and its effect on crop yields. Bozsik (1996) carried out studies on the aphicidal efficiency of different nettle extracts. The cold-water extract had no significant effect on Hyalopterus pruni Geoffroy and Cryptomyzus ribis Linnaeus; the fermenting extract hardly influenced $H$. pruni and no significant efficiency was observed against Aphis spiraephaga F.P. Müller (Bozsik, 1996). Rosnitschek-Schimmel (1985) showed that the most important nitrogen compound in nettle plants was free amino acids, of which asparagine and arginine accounted for up to $80 \%$. These nitrogen compounds were stored mainly in roots and rhizomes (Rosnitschek-Schimmel, 1985).

The chemical composition of several green solid manure, including nettle, was compared by Sorensen and Thorup-Kristensen (2011). They concluded that nettle manure had high concentrations of boron (B), and that the low $\mathrm{C}: \mathrm{N}$ ratios of green manures had a stronger impact on plant production than the total amount of $\mathrm{N}$ through solid soil applications (Sorensen \& Thorup- 
Kristensen, 2011). To our knowledge, no scientific analysis of the effect of nettle slurry on horticultural crop yields with different doses has been published.

In this study, we aimed to analyze the possible effect of nettle slurry on potato yields produced by organic farming. To achieve this main objective, we aimed to assess: (i) the effect of nettle slurry on potato yields; (ii) the influence of slurry on potato plant size and growth parameters; (iii) its effect on chlorophyll content; (iv) its possible influence on the presence of pests and diseases. Different slurry doses were assessed in 36 plots and nine variables were measured during the crop cycle. We designed a robust randomized complete block experiment, coded for unbiased management, with many repetitions. The experiment was conducted under organic agricultural conditions.

\section{Materials and Methods}

\section{Experimental design}

In this experiment, six treatments were planned; three with different Urtica doses (A to C) as so: one with Urtica and Equisetum slurry (D); one with conventional foliar manure (E); one control treatment (F) treated only with water (Fig. 1). The experiment was run with a randomized complete block design (RCBD) with six replicates per treatment and 36 plots distributed in six blocks. Each plot was $5 \mathrm{~m}$ long and $3 \mathrm{~m}$ wide ( 3 ridges) and each plot covered $15 \mathrm{~m}^{2}$ (Fig. 1). All the plants in each plot were treated. However, measurements were only taken in the three central meters of the central ridge to avoid the edge effect (Fig. S1). Plots were coded for unbiased management.

\section{Fig. 1. Experimental design.}

\section{Experimental site}

The experiment was conducted in the town of Godella in the province of Valencia, Spain (39 $31^{\prime}$ $12.9^{\prime \prime} \mathrm{N}, 0^{\circ} 24^{\prime} 34.9^{\prime \prime} \mathrm{W}$ ) in a calcareous silty clay loam alluvial soil from February to June 2016. The general site climate is Mediterranean oceanic, with a long-term average annual rainfall of 468 $\mathrm{mm}$ and an average annual air temperature of $17^{\circ} \mathrm{C}$ (w.s. 39 $29^{\prime} \mathrm{N} 0^{\circ} 23^{\prime} \mathrm{W} 13 \mathrm{~m}$ a.s.1.). In 2016, the annual rainfall was $382 \mathrm{~mm}$ and it rained $58 \mathrm{~mm}$ during the experimental period. The plot was fertilized once at the beginning of the experiment before sowing. For this, horse manure ( $25 \mathrm{t} / \mathrm{ha})$ was used. Subsequently, no additional soil fertilization was carried out; therefore, the use of nettle slurry was the essential fertilizer in our fertilization program. The plot was prepared and managed and ridges were built in collaboration with a local organic farmer. Eighty kilograms of the Dutch potato variety "agria" was sown for the experiment. The total cycle lasted 107 days, with five irrigation sessions (Table 1).

\section{Table 1. Main management events schedule (month/day).}

\section{Soil, water and slurry chemical analyses}

The site soil was analyzed at the start of the experiment. The experimental site was divided into four equal plots for soil sampling (A, B, C, D; Table 2). Each sample resulted from mixing five uniformly distributed soil subsamples (detail of subsamples location in Fig. S1). Soil analyses were 
129

130

131

132

133

134

135

136

137

138

139

140

141

142

143

144

145

146

147

148

149

150

151

152

153

154

155

156

157

158

159

160

161

162

163

164

165

166

167

168

169

170

carried out in the laboratory following standard protocols (AOAC, 1995). Electrical conductivity, $\mathrm{pH}$, organic matter, calcium carbonate, total nitrogen, and available potassium, sodium, phosphorus, calcium and magnesium, were determined per soil sample. For each soil parameter, high $(\mathrm{H})$, medium $(\mathrm{M})$ and low $(\mathrm{L})$ levels were assigned according to previous studies in the same geographical area (Jackson, 1976; Villalbi \& Vidal, 1988; Guigou et al., 1989; Legaz et al., 1995). The water analysis results were provided by Ambitec laboratorios (laboratory reference: 7938A) using a standard methodology (Table 3). Electrical conductivity, $\mathrm{pH}$, organic matter, ash (\%), $\mathrm{K}_{2} \mathrm{O}$ $(\%), \mathrm{P}_{2} \mathrm{O}_{5}(\%)$, total $\mathrm{N}(\%)$ and protein were determined for Urtica and Equisetum slurry (Table 4). Slurry analyses were carried out in the laboratory following standard protocols (Horwitz, 1989). Slurry chemical analyses were redone several times and with different batches to confirm the obtained values.

\section{Treatments}

Commercial foliar fertilizers were used to prepare the treatment solutions. The Urtica dioica slurry (fermenting extract) and the Equisetum hyemale slurry came from the "Ortiga Amiga" trading house (Spanish company tax code (NIF) 46339215b). The base substance was produced according to regulation (EC) No. 1107/2009. The recommended Urtica and Equisetum slurry dose (RD) was $10 \% \mathrm{v} / \mathrm{v}$. The conventional foliar manure was "Isabión" from the Syngenta trading house. The Isabión label indicates $10.9 \%$ of total nitrogen. The recommended Isabión dose was 200-300 $\mathrm{cc} / 1001$ of water.

Following the company recommendations, in a 10-liter final volume solution the following volumes of foliar fertilizers were added to water: for treatment A (RD) 11; for treatment B ( $1 / 2 \mathrm{RD})$ 0.51; for treatment C (2xRD) 21; for treatment D 11 of the Urtica and 11 of Equisetum slurry; for treatment E $25 \mathrm{ml}$ of the conventional foliar manure. Control treatment F was composed of only water. Slurry was applied using a 151 knapsack sprayer, to which we added a conical nozzle (PULMIC) to ensure a constant pressure of 2.5 bar. Treatments were applied 3 times throughout the crop cycle (Table 1). In the first application, plants displayed the first four true leaves $\left(15^{\text {th }}\right.$ April); in the second, plants flowered (May 4); and in the third, plants had fully developed and came closer to the end of the cycle (May 23).

\section{Measurements}

Crop yields, expressed as $\mathrm{kg}$ of potatoes, were determined by harvesting the central 3 meters of the central ridge (Fig. S1). Three samplers worked at the same time by harvesting 1 meter each to obtain three measurements per plot. The sampler effect was analyzed with no significant differences found among samplers (Fig. S2 Samplers). Five parameters related to plant growth and size were measured. Height, number of leaves and leaf length were measured 3 times throughout the plant's growth cycle (T1 is April 14, T2 is May 3, and T3 is June 1), while the number of flowers (May 3) and the final biomass (June 11) were measured once (Table 1). Each parameter was measured on five individuals from all 36 plots $(n=180)$. 
171 Three leaf samples from different individuals in each plot (108 samples) were taken for the 172 chlorophyll analyses. Sampling was performed when plants had fully developed on June 1 (Table

173 1). Chlorophylls were extracted with acetone protocol (Val, Heras \& Monge, 1985) and their 174 content was determined by absorbance spectrophotometry at wavelengths 645, 652 and $663 \mathrm{~nm}$. 175 The presence of pests and diseases was observed 3 times (T1, T2 and T3). Each time, five plants 176 were noted per repetition and treatment $(\mathrm{n}=180)$. Only Colorado potato beetle (Leptinotarsa 177 decemlineata Say) and potato blight (Phytophthora infestans (Mont.) de Bary) were found.

178

179

180

181

182

183

184

185

186

187

188

189

190

191

192

193

194

195

196

197

198

199

200

201

202

203

204

205

206

207

208

209

210

211

212

213

\section{Statistical analysis}

The average, standard error, skew, kurtosis, frequency distribution and density curve of the yields were assessed for each treatment. ANOVAs were used to compare the mean values between treatments and blocks. Shapiro-Wilk tests were calculated to check normality requirements. In some cases due to lack of normality, nonparametric methods were selected to compare the means among treatments and blocks by a Kruskal-Wallis rank sum test. When significant differences were found, Levene's test and eta-squared statistics were calculated to assess the homogeneity of variances and the effect size in the ANOVA, respectively. Tukey Honest Significant Difference (HSD) was selected as the post hoc test.

To exclude the block effect (watering) from the main effect (yield), the residuals from the block ANOVAs were compared. Linear models were selected to analyze the effect of numerical variables (plant size and chlorophyll variables) on yield, while Pearson correlations were calculated to assess the relationships between independent variables. A principal component analysis (PCA) was used to analyze how the chlorophyll parameters were related. All the statistical analyses were done using R (R Core Team 2017) with some extra packages: car (Fox \& Weisberg, 2011); plotrix (Lemon, 2006); ggpubr (Kassambara, 2017); agricolae (Mendiburu, 2017); vcd (Meyer, Zeileis \& Hornik, 2006); writexl (Ooms, 2017); ggplot2 (Wickham, 2009); readxl (Wickham \& Bryan, 2017); plyr (Wickham, 2011); tidyr (Wickham \& Henry, 2017) and knitr (Xie, 2017).

\section{Results}

\section{Soil, irrigation water and slurry chemical composition}

Soil nutrient status was homogeneous throughout the site (Table 2). Although natural organic matter (NOM) contents were medium and high, the presence of high levels of carbonates and $\mathrm{C} / \mathrm{N}$ ratio indicated a slow release of nitrogen to soil. Therefore, the total nitrogen value in soil was low. We obtained homogeneous $\mathrm{pH}$ values, which indicates strongly alkaline soil (average $\mathrm{pH}$ of 8.6; Table 2).

\section{Table 2. Site soil analysis at 4 points $A, B, C, D$.}

The irrigation water analyses indicated a low-medium nitrate content (Table 3). According to Riverside classification C3-S1, water salinity was medium, and therefore, appropriate to irrigate well-drained soil (Aragues et al., 1979). The analyses showed a high content of carbonates and soluble potassium, and a low sodium content (Table 3). 
214

215

216

217

218

219

220

221

222

223

224

225

226

227

228

229

230

231

232

233

234

235

236

237

238

239

240

241

242

243

244

245

246

247

248

249

250

251

252

253

254

255

\section{Table 3. Irrigation water analysis.}

The slurry chemical analyses indicated neutral $\mathrm{pH}$ values (7.6-7.9) and medium electrical conductivity (1.2-1.3mS) (Table 4). Very low levels of macronutrients (N-P-K) were obtained for both slurries. Nettle slurries from other trading houses were also analyzed with similar low levels of macronutrients (Table S1).

\section{Table 4. Slurry chemical analysis.}

\section{Effect of nettle slurry on potato yields}

Including all the treatments, 36 plots were treated and 108 yield weight measures were recorded (Fig. 1 and Fig. S3). The ANOVA for the effect of treatments on yields showed no significant differences among treatments $\left(\mathrm{p}=0.7697, \mathrm{R}^{2}=0.0243\right)$. With the control treatment, a mean of $2.35 \mathrm{~kg} / \mathrm{m}$ of potatoes were collected, while the mean was $2.16 \mathrm{~kg} / \mathrm{m}$ with the recommended nettle treatment dose (A), and no significant differences were found (Table 5). None of the evaluated Urtica doses (recommended dose, half the recommended dose, double the recommended dose and Urtica in combination with Equisetum), meaning 24 independent plots, showed any significant increase in potato tuber yields compared with the control treatment (Table 5 and Fig. 2).

\section{Table 5. Average yield achieved in each treatment $(\mathrm{kg} / \mathrm{m})$.}

Fig. 2. Effect of treatments on yield $(\mathrm{kg} / \mathrm{m})$ with all the data (102 degrees of freedom).

In order to check whether there was any overlapping factor that masked the possible effect of nettle slurry on potato yields, we analyzed whether there were any significant differences between blocks (Table S2 and Fig. S4). The ANOVA for the effect of blocks on yield showed significant differences $\left(p=0,0004, R^{2}=0.3743\right)$. The mean yield values increased from block 1-2 (closer to the water entry point) to block 5-6 (far away from the water entry point). Accordingly, the watering effect was analyzed. Due to the plot slope, a similar amount of water was applied to blocks 1 and 2, blocks 3 and 4, and blocks 5 and 6 (Fig. 1). Therefore, pairs of blocks were used to analyze the effect of watering (Table 6 and Fig. 3). Significant differences among watering blocks were observed $\left(\mathrm{p}=4.1507^{\wedge}\{-4\}, \mathrm{R}^{2}=0.1378\right)$, with a yield reduction as blocks approached the water entry point (e.g. $1.97+-0.08 \mathrm{~kg} / \mathrm{m}$ for B1-2, and $2.57+-0.12 \mathrm{~kg} / \mathrm{m}$ for B5-6) (Table 6).

\section{Table 6. Average yield achieved in each block pair $(\mathrm{kg} / \mathrm{m})$.}

Fig. 3. Effect of watering by block pairs on yield $(\mathrm{kg} / \mathrm{m})$.

The ANOVA for the effect of treatments on yield, excluding the watering effect, showed no significant differences among treatments $\left(\mathrm{p}=0.7065, \mathrm{R}^{2}=0.0282\right.$; Fig. 4$)$. F value, $\mathrm{p}$ value and HSD changed slightly by eliminating the effect of block pair, but not enough to be significant. Consequently, none of the nettle treatments resulted in significantly increased tuber production after excluding the watering effect. When considering only tendencies (as differences were non 
256 significant), the plants treated with the half dose and the control treatment yielded more tuber

257

258

259

260

261

262

263

264

265

266

267

268

269

270

271

272

273

274

275

276

277

278

279

280

281

282

283

284

285

286

287

288

289

290

291

292

293

294

295

296

297

298

kilograms than those with the recommended nettle dose (Table 5).

Fig. 4. Effect of treatments on yield $(\mathrm{kg} / \mathrm{m})$ with the residuals of the Block Pair ANOVAs.

The interaction between treatments and block pairs (Fig. 5 and Table S3) showed that a higher yield was obtained in block pair 5-6 for all the treatments. Inside the block pair, differences among treatments (Table S3) were not significant in any case.

\section{Fig 5. Mean yield values for treatments and block pairs.}

\section{Influence of nettle slurry on potato growth and plant size parameters}

The results of measuring the growth and size parameters (height, number of leaves, leaf length measured at T1, T2 and T3, number of flowers, and the final biomass measured once) are provided in Table 7. The ANOVA showed that the effect of treatments on these parameters was weak, with only some significant differences (Table 8). The analyses of plant height and number of flowers, both at T2, were not meaningful because the standard deviations were not homogenous among treatments (Levene's test in Table 8). The ANOVA for plant height at T3 showed significant differences $(p=0.0051)$, which indicates that the plants treated with a double RD (mean of 67.27 $\mathrm{cm})$ were slightly higher at the end of the cycle than the control treatment (mean of $60.13 \mathrm{~cm}$ ), with significant differences even though the effect size was small $\left(\eta^{2}=0.09\right)$ (Fig. 6).

The ANOVA for leaf length at T1 also showed significant differences $(p=0.00001)$, which indicates that initially the leaves treated with slurry (RD and $1 / 2 \mathrm{RD}$ ) were larger than those from the control (e.g. $21.9+-0.6 \mathrm{~cm}$ for $1 / 2 \mathrm{RD}$, and $16.4+-1 \mathrm{~cm}$ for the control), although this effect disappeared as plants grew (T2 and T3) (Fig. 6). The differences in the number of leaves among treatments were significant at all times, but effect sizes were small $\left(\eta^{2}=0.09\right.$ for $\mathrm{T} 1$ and $\eta^{2}=0.07$ for T3). A variation at T2 of only two leaves between the lowest (13.7) and highest (15.7) mean values was found. Nevertheless, the results of number of leaves were not consistent as the plants treated with the slurry RD had two leaves less than those of the control treatment, while the plants treated with the $1 / 2 \mathrm{RD}$ had the same number of leaves as the control treatment (15.7). Aerial biomass was also evaluated at the end of the cycle, and no significant differences among treatments were found (Table 8).

Table 7. Mean and standard error of the size and growth variables for each treatment.

Table 8. ANOVA and post hoc Tukey test performed with the residuals of the Block Pair.

Fig 6. Effect of treatments on the plant size variables at times 1, 2 and 3.

\section{Influence of treatments on chlorophyll content}

Ten days before harvest, three leaves per plot were collected for chlorophyll determination purposes $(\mathrm{n}=108)$. A chlorophyll, B chlorophyll, total chlorophyll 1 and total chlorophyll 2 were 
299

300

301

302

303

304

305

306

307

308

309

310

311

312

313

314

315

316

317

318

319

320

321

322

323

324

325

326

327

328

329

330

331

332

333

334

335

336

337

338

339

340

341

calculated with the absorbance data. No significant differences in the leaf chlorophyll content among treatments were observed (total chlorophyll $2 \mathrm{p}$ value $=0.3186)$ (Table 9$)$. The chlorophyll parameters correlated highly (Fig. S5), therefore total chlorophyll 2, which was nearly parallel to Principal Component 1, was selected to analyze the effects of chlorophylls (Fig. S6). The plants treated with double RD had the highest total chlorophyll 2 content (mean value of $0.82 \mathrm{mg} / \mathrm{g}$ ), but no significant differences compared with other treatments were found (Table 9).

Table 9. Chlorophyll A, B and total Chlorophyll content by treatment.

\section{Effect on pests and presence of diseases}

Pests and presence of diseases were recorded at three different times and in five plants from each plot. The Colorado beetle Leptinotarsa decemlineata appeared at T2 and slightly decreased at T3 (Fig. 7), whereas Phytophthora infestans appeared only at T3 for all treatments and water regimes, except for treatment E (Fig. 8). The Chi-square tests for pest occurrence were done to compare treatments. Nevertheless, there were not enough expected values for the pests present analyses, which indicates that it was not possible to correctly assess significant differences among treatments. Similar small amounts of pests were observed in all the treatments, and low levels of pests present indicated that no treatment significantly increased the appearance of pests.

Fig. 7. Mosaic plot for the presence of Leptinotarsa decemlineata for different times, treatments and watering regimes

\section{Fig. 8. Mosaic plot for the presence of Phytophthora infestans for different times, treatments and watering regimes.}

\section{Correlations among the evaluated variables}

Plant size and the chlorophyll parameters did not affect yield, while some of these parameters were affected by treatments or watering. Chlorophyll content was not affected by watering blocks ( $\mathrm{p}>$ $0.05)$, but correlated positively with biomass $(\mathrm{R}=0.54)$, height $(\mathrm{R}=0.62)$ and number of leaves $(\mathrm{R}=0.47)$ at $\mathrm{T} 3$, and to a lesser extent at $\mathrm{T} 2$. These findings indicate that large plants had a higher chlorophyll content.

Pests and diseases did not correlate with one another, nor with yield ( $\mathrm{R}=0.06$ for beetle; $\mathrm{R}=0.18$ for blight) or watering blocks. Phytophthora infestans correlated negatively with plant height (R $=-0.52)$, number of leaves $(R=-0.57)$ and number of flowers $(R=-0.44)$, which indicates that this disease appeared more frequently in small or weak plants. The plant size parameters correlated highly with one another (i.e. $\mathrm{R}=0.70$ for height $\mathrm{T} 3$-number of leaves $\mathrm{T} 3$ ), but surprisingly did not relate with yield or watering blocks (R2 between $0.01-0.001$ and $\mathrm{p}>0.05)$.

\section{Discussion}

Nettle slurry foliar fertilizer treatments (including Urtica combined with Equisetum) did not have any effect on yield, chlorophyll content or the presence of pest and diseases of potato organic crops 
342

343

344

345

346

347

348

349

350

351

352

353

354

355

356

357

358

359

360

361

362

363

364

365

366

367

368

369

370

371

372

373

374

375

376

377

378

379

380

381

382

383

384

grown under these field experimental conditions. The results showed slightly improved plant appearance with higher plants at the end of the growth cycle.

Quite often several positive effects are attributed to nettle slurry, but they are based on very little scientific evidence. One of the main attributed effects is its ability to stimulate plant growth and to, therefore, improve yield due to its higher nutrient concentrations (nitrogen and others). Nitrogen is a major element in plants and is assimilated in free amino acids, proteins, and other nitrogenous compounds that are related to growth and development (Ruamrungsri et al., 2010). In nettle, the most important nitrogen is stored in roots and rhizomes (Rosnitschek-Schimmel, 1985). The chemical analyses performed during this experiment showed a very low total nitrogen content of the Urtica slurry $(0.005 \%)$ and the Equisetum slurry $(0.002 \%)$. This result was confirmed several times in different batches. Sorensen and Thorup-Kristensen (2011) obtained between 2.2\% and $3.3 \%$ of nitrogen $[\mathrm{N}]$ in a nettle dry chopped solid green manure. Therefore, nettle solid green manure probably has more nitrogen than liquid slurries. Moreover within a plant species, the chemical composition of green manure is influenced by the developmental stage (Sorensen \& Thorup-Kristensen, 2011). The concentration of most nutrients usually decreases during plant ontogeny (Kirchmann \& Bergqvist, 1989; Sorensen, 2000) due to a dilution effect (Jarrell \& Beverly, 1981). Consequently, the nettle slurry total content of $\mathrm{N}$ and other nutrients may vary depending on many factors. In addition, better labeling and more frequent chemical analyses of commercial products would be desirable.

Sorensen and Thorup-Kristensen (2011) found that when applied to soil, differences in the effect of solid green manures were not due to the total amount of $\mathrm{N}$ applied, but to $\mathrm{N}$ availability and to the carbon-to-nitrogen $(\mathrm{C}: \mathrm{N})$ ratio. The green manure $\mathrm{C}: \mathrm{N}$ ratio also varied with the developmental stage. The best responses on cauliflower, kale, leek and celery are observed when applied to soil green manures with low C:N ratios (Sorensen \& Thorup-Kristensen, 2011).

In nettle, the most important nitrogen compounds are free amino acids, of which asparagine and arginine consist up to $80 \%$ (Rosnitschek-Schimmel, 1985). No studies have been found on the chemical type of nitrogen present in nettle slurry and how potato leaves absorb this N. Assimilation of ammonium and nitrate by potato plants from soil or culture solution has been studied many times in the past (Street, Kenyon \& Watson, 1946), but absorption through potato leaves when nitrogen is applied as a foliar fertilizer has not yet been studied.

Nevertheless, nitrogen might not be the only key. Micronutrients can improve the efficient use of macronutrients (Malakouti, 2008). Therefore, the Urtica and Equisetum slurry could hypothetically improve potato yields due to the supplied micronutrients, which was not the case. One of the most efficient foliar natural fertilizers is seaweed (Dhargalkar \& Pereira, 2005; Akila \& Jeyadoss, 2010; Chbani, Mawlawi \& Zaouk, 2013), which has been recently tested on potato (Pramanick et al., 2017). Seaweed (Kappaphycus alvarezii (Doty) Doty ex Silva) foliar extract application, combined with a varied dose of soil fertilizers $(50 \%, 75 \%$ and $100 \%$ RDF, where RDF $=200: 150: 150 \mathrm{~kg} \mathrm{ha}^{-1}$ of $\mathrm{N} / \mathrm{P}_{2} \mathrm{O}_{5} / \mathrm{K}_{2} \mathrm{O}$, respectively) improved the plant height, yield, and chlorophyll content of potato plants (Pramanick et al., 2017). In this case, the authors pointed out 
385

386

387

388

389

390

391

392

393

394

395

396

397

398

399

400

401

402

403

404

405

406

407

408

409

410

411

412

413

414

415

416

417

418

419

420

421

422

423

424

425

426

427

the fact that K-sap (Kappaphycus extract) is a rich source of several primary nutrients, like potassium and phosphorus, of secondary nutrients like calcium and magnesium, and also trace elements like zinc, copper, iron and manganese. As a broad source of potassium, K-sap helped in the translocation of photosynthates to tubers (Zodape et al., 2010). These results highlight how foliar and soil fertilization can be related, as well as the importance of other nutrients other than only nitrogen. In our experiment, the conventional foliar manure treatment, which had only a high nitrogen content, but no phosphorus or potassium, did not show any significant differences with the control treatment (only a small dose of $0.25 \% \mathrm{v} / \mathrm{v}$ was tested). This result could indicate limited nitrogen absorption ability through potato leaves and the need for other elements to be present like phosphorus or potassium.

Another attributed effect of nettle slurry is its ability to stimulate microbial activity on soil, but once again, very little evidence is available. This effect would be more related with soil applications (not assessed in these experiments), to the carbon, nitrogen and other elements supplied with slurry, and to its own microbial load. No data on microbial load or the microbial activity in relation with nettle slurry have been found. Nettle slurry is also commonly used in soil applications. Perhaps in these cases, an assumed increase in microbial activity would improve plant fertilization, which has not yet been tested.

The ability to increase chlorophyll content is also attributed to nettle slurry. In this experiment, nettle slurry treatments did not significantly increase chlorophyll content. Nevertheless, the highest chlorophyll content was found in the double dose treatment, but the difference was not significant. This result, together with only a minor improvement in plant height with the double dose treatment, might suggest minimum crop improvement which, in our experimental conditions, was not enough to improve yields.

Finally, slurry is supposed to improve pest and disease prevention due to an increase in epidermal cell walls thickness. Very few studies about the effect of nettle slurry on pest and disease were found. Bozsik (1996) studied the aphicidal efficiency of cold water and fermenting nettle slurries, which had a very low or non significant effect on aphids like Hyalopterus pruni, Cryptomyzus ribis or Aphis spiraephaga (Bozsik, 1996). In agreement with these studies, presence of pests and disease gave no significant differences among treatments.

\section{Conclusions}

The use of nettle slurry as a foliar fertilizer was assessed for the first time. Under these field experimental conditions, nettle slurry (including one treatment with Urtica in combination with Equisetum) had no significant effects on yield, chlorophyll content or presence of pests and diseases in potato organic crops. We achieved a slight increase in plant growth, but it had no consequences on yield. Very low levels of nitrogen, phosphorus and potassium were obtained for the Urtica and Equisetum slurry. Very few studies are available on nettle slurry and, consequently, a lot of information is lacking. The chemical composition of fermented liquid slurry and its variability has been scarcely studied. The use of either slurry as a foliar fertilizer on other 
428 horticultural crops or liquid slurry in soil applications has not been assessed. Therefore, many more 429 studies are needed to unravel whether nettle slurry is useful or not for improving horticultural 430 organic crops, and which mechanisms are involved.

431

\section{Acknowledgment}

433 The authors thank the organic farmer Francisco Morcillo for his collaboration in the management 434 of the plot.

435

436

\section{Supporting information}

437 Fig. S1 Measurement design

438 Fig. S2 Samplers

439 Table S1

440 Fig. S3 Yield data distribution

441 Table S2. Summary yield_block

442 Fig. S4 Yield_block

443 Table S3. Yield block_treatment interaction

444 Fig. S5 Clorophyll_correlations

445 Fig. S6 PCA Chlorophyll_biplot

446

447

448

\section{References}

Akila N., Jeyadoss T. 2010. The potential of seaweed liquid fertilizer on the growth and antioxidant enhancement of Helianthus annuus L. Oriental Journal of Chemistry 26:1353.

AOAC. 1995. Official methods of analysis of AOAC International. AOAC International USA. I.

Apaolaza V., Hartmann P., D’Souza C., Lopez CM. 2018. Eat organic - Feel good? The relationship between organic food consumption, health concern and subjective wellbeing. Food Quality and Preference 63:51-62. DOI: 10.1016/j.foodqual.2017.07.011.

Aragues R., Alberto F., Cuchi JA., Machin J. 1979. [Quality of the waters for irrigation, 1: General

Benfatto D., Matteo R., Di Franco F., San Lio RM., Ugolini L., Lazzeri L. 2015. The use of bio-based liquid 457 formulations in pest control of citrus groves. INDUSTRIAL CROPS AND PRODUCTS 75:42-47. DOI: 10.1016/j.indcrop.2015.05.039.

Benítez Cruz G. 2009. Etnobotánica y etnobiología del Poniente Granadino. Facultad de Farmacia. Universidad de Granada. 
461 Bozsik A. 1996. Studies on aphicidal efficiency of different stinging nettle extracts. Anzeiger Fur 462 Schadlingskunde Pflanzenschutz Umweltschutz 69:21-22. DOI: 10.1007/BF01905863.

463 Branisa J., Jomova K., Porubska M., Kollar V., Simunkova M., Valko M. 2017. Effect of drying methods on

464

465

466

467

468

469

470

471

472

473

474

475

476

477

478

479

480

481

482

483

the content of natural pigments and antioxidant capacity in extracts from medicinal plants: a spectroscopic study. CHEMICAL PAPERS 71:1993-2002. DOI: 10.1007/s11696-017-0193-9.

Buenz EJ., Parry GJ., Bauer BA., Howe CL., Hammond-Tooke G., Tsuchihara T., Kanzaki M., Peacey M. 2017. A POTENTIAL THERAPEUTIC FOR CHRONIC PAIN FROM THE NEW ZEALAND NATIVE STINGING NETTLE URTICA FEROX (ONGAONGA). JOURNAL OF NEUROLOGY NEUROSURGERY AND PSYCHIATRY 88. DOI: 10.1136/jnnp-2017-316074.11.

Chbani A., Mawlawi H., Zaouk L. 2013. Evaluation of brown seaweed (Padina pavonica) as biostimulant of plant growth and development. African Journal of Agricultural Research 8:1155-1165.

Dhargalkar VK., Pereira N. 2005. Seaweed: promising plant of the millennium.

Di Virgilio N., Papazoglou EG., Jankauskiene Z., Di Lonardo S., Praczyk M., Wielgusz K. 2015. The potential of stinging nettle (Urtica dioica L.) as a crop with multiple uses. Industrial Crops and Products 68:42-49.

Fox J., Weisberg S. 2011. An R Companion to Applied Regression. Thousand Oaks CA: Sage.

Gagic V., Kleijn D., Baldi A., Boros G., Jorgensen HB., Elek Z., Garratt MPD., de Groot GA., Hedlund K., Kovacs-Hostyanszki A., Marini L., Martin E., Pevere I., Potts SG., Redlich S., Senapathi D., SteffanDewenter I., Switek S., Smith HG., Takacs V., Tryjanowski P., van der Putten WH., van Gils S., Bommarco R. 2017. Combined effects of agrochemicals and ecosystem services on crop yield across Europe. ECOLOGY LETTERS 20:1427-1436. DOI: 10.1111/ele.12850.

Gomiero T. 2017. Food quality assessment in organic vs. conventional agricultural produce: Findings and issues. Applied Soil Ecology. 
484 Guigou B., Thonnelier B., Duzan B., Felix-Faure B. 1989. Pour valoriser les analyses de sol. Purpan (Ed)

485

486

487

488

489

490

491

492

493

494

495

496

497

498

499

500

501

502

503

504

505

506

507 134:3-88.

Horwitz W. 1989. Methods of analysis, AOAC. Washington DC, USA: Association of Analytical Chemists. Jackson ML. 1976. Análisis químico de suelos. Trad. al español por José Beltrán Martínez. Omega. Barcelona, España:282-283.

Jarrell WM., Beverly RB. 1981. The dilution effect in plant nutrition studies. Advances in agronomy 34:197-224.

Kahl J., Rembia Vkowska E. 2014. Research on organic food quality needs a system approach. Journal of the Science of Food and Agriculture 94:2577-2577.

Kassambara A. 2017. ggpubr: "ggplot2" Based Publication Ready Plots.

Kirchmann H., Bergqvist R. 1989. Carbon and nitrogen mineralization of white clover plants (Trifolium repens) of different age during aerobic incubation with soil. Journal of Plant Nutrition and Soil Science 152:281-286.

Latorre JA. 2008. Estudio etnobotánico de la provincia de La Coruña. Facultad de Farmacia. Universidad de Valencia.

Legaz F., Serna MD., Ferrer P., Cebolla V., Primo-Millo E. 1995. Análisis de hojas, suelos y aguas para el diagnóstico nutricional de plantaciones de cítricos. Procedimiento de toma de muestras. Generalitat Valenciana 27.

Lemon J. 2006. Plotrix: a package in the red light district of R. R-News 6:8-12.

Lernoud J., Willer H. 2017. The World of Organic Agriculture. Statistics and Emerging Trends 2017. Organics International, Bonn: Research Institute of Organic Agriculture (FiBL), Frick, and IFOAM.

Lobley M., Butler A., Reed M. 2009. The contribution of organic farming to rural development: An exploration of the socio-economic linkages of organic and non-organic farms in England. Land Use Policy 26:723-735. 
508 Malakouti MJ. 2008. The effect of micronutrients in ensuring efficient use of macronutrients. Turkish Journal of Agriculture and Forestry 32:215-220.

Mendiburu F de. 2017. agricolae: Statistical Procedures for Agricultural Research.

511

512

513

514

515

516

517

518

519

520

521

522

523

524

525

526

527

528

529

530

Meyer D., Zeileis A., Hornik K. 2006. The Strucplot Framework: Visualizing Multi-Way Contingency Tables with ved. Journal of Statistical Software 17:1-48.

Michelsen J. 2001. Recent development and political acceptance of organic farming in Europe. Sociologia Ruralis 41:3-+. DOI: 10.1111/1467-9523.00167.

OJ. 2009. Regulation (EC) No. 1107/2009 of the European Parliament and of the Council concerning the placing of plant protection products on the market and repealing Council Directives 79/117/EEC and 91/414/EEC. Official Journal of the European Union L:1-50.

Ooms J. 2017. writexl: Export Data Frames to "xlsx" Format.

Pramanick B., Brahmachari K., Mahapatra BS., Ghosh A., Ghosh D., Kar S. 2017. Growth, yield and quality improvement of potato tubers through the application of seaweed sap derived from the marine alga Kappaphycus alvarezii. Journal of Applied Phycology 29:3253-3260. DOI: 10.1007/s10811017-1189-0.

Reganold JP., Wachter JM. 2016. Organic agriculture in the twenty-first century. Nature Plants 2:15221.

Rosnitschek-Schimmel I. 1985. Seasonal dynamics of nitrogenous compounds in a nitrophilic weed I. Changes in inorganic and organic nitrogen fractions of the different plant parts of Urtica dioica. Plant and cell physiology 26:169-176.

Ruamrungsri S., Kuankaew T., Ohtake N., Sueyoshi K., Ohyama T. 2010. 22. Nitrogen assimilation in flower bulbs.

Saeidi AsI MR., Adel M., Caipang CMA., Dawood MAO. 2017. Immunological responses and disease resistance of rainbow trout (Oncorhynchus mykiss) juveniles following dietary administration of 
stinging nettle (Urtica dioica). Fish \& shellfish immunology 71:230-238. DOI:

532 10.1016/j.fsi.2017.10.016.

Sorensen JN. 2000. Ontogenetic changes in macro nutrient composition of leaf-vegetable crops in relation to plant nitrogen status: A review. Journal of Vegetable Crop Production 6:75-96.

Sorensen JN., Thorup-Kristensen K. 2011. Plant-based fertilizers for organic vegetable production. Journal of Plant Nutrition and Soil Science 174:321-332. DOI: 10.1002/jpln.200900321.

Street H., Kenyon A., Watson G. 1946. The Assimilation of Ammonium and Nitrate Nitrogen by Detached

Val J., Heras L., Monge E. 1985. Nuevas ecuaciones para la determinación de pigmentos fotosintéticos en acetona. In: Anales de la Estación Experimental de Aula Dei. 231-238.

Villalbi I., Vidal M. 1988. Análisis de suelos y foliares: Interpretación y fertilización. Fundación Caja de Pensiones. Barcelona.

Wickham H. 2009. ggplot2: Elegant Graphics for Data Analysis. Springer-Verlag New York. 40:1-29.

Wickham H., Bryan J. 2017. readxl: Read Excel Files.

Wickham H., Henry L. 2017. tidyr: Easily Tidy Data with "spread()" and "gather()" Functions.

Xie Y. 2017. knitr: A General-Purpose Package for Dynamic Report Generation in R. Durovic S. 2017. Chemical and biological screening of stinging nettle leaves extracts obtained by modern extraction techniques. INDUSTRIAL CROPS AND PRODUCTS 108:423-430. DOI: 10.1016/j.indcrop.2017.06.055. 
554 Zodape ST., Mukhopadhyay S., Eswaran K., Reddy MP., Chikara J. 2010. Enhanced yield and nutritional

555 quality in green gram (Phaseolus radiata L) treated with seaweed (Kappaphycus alvarezii)

$556 \quad$ extract.

557 


\section{Table $\mathbf{1}$ (on next page)}

Main management events schedule (month/day).

T. application, treatment application; measurement (1) (2) and (3) corresponds to T1, T2 and T3. 


\begin{tabular}{|c|c|c|c|c|c|c|}
\hline $2 / 26$ & $3 / 14$ & $3 / 28$ & $4 / 4$ & $4 / 14$ & $4 / 14$ & $4 / 14$ \\
\hline Sowing & Irrigation (1) & Irrigation (2) & Rainfall & Re-ridge & Plot design & Measurement (1) \\
\hline $4 / 14$ & $4 / 15$ & $4 / 16$ & $\begin{array}{r}4 / 25 \\
\text { Irrigation }\end{array}$ & $5 / 3$ & $5 / 4$ & $5 / 23$ \\
\hline Soil samples & T. application (1) & Irrigation (3) & (4) & Measurement (2) & T. application (2) & T. application (3) \\
\hline $5 / 23$ & $6 / 1$ & $6 / 1$ & $6 / 6$ & $6 / 10$ & $6 / 11$ & $6 / 11$ \\
\hline Irrigation (5) & Measurement (3) & $\begin{array}{r}\text { Chlorophyll } \\
\text { samples }\end{array}$ & $\begin{array}{r}\text { Irrigation } \\
(6)\end{array}$ & Aerial biomass & Harvest & Tuber size \\
\hline
\end{tabular}

1 


\section{Table 2 (on next page)}

Site soil analysis at 4 points $A, B, C, D$.

Symbols and units are: $\mathrm{Ca}$, calcium (mep/100g); $\mathrm{Mg}$, magnesium (mep/100g); $\mathrm{K}$, potassium (mep/100g); $\mathrm{Na}$, sodium (mep/100g); P, phosphorus (mg/Kg dry soil); Total $\mathrm{N}$, total nitrogen (\%); Carbonates (\%); NOM, natural organic matter (\%); C/N, nitrogen carbon ratio; EC, soil electrical conductivity $(\mu \mathrm{S}) ; \mathrm{pH} \mathrm{W}, \mathrm{pH}$ in water; $\mathrm{pH}$ in $\mathrm{KCl}$. 


\begin{tabular}{|c|c|c|c|c|c|c|c|c|c|c|c|c|c|c|c|c|c|c|c|c|c|}
\hline & $\mathrm{Ca}$ & & $\mathrm{Mg}$ & & $\mathrm{K}$ & & $\mathrm{Na}$ & & $\mathrm{P}$ & & $\begin{array}{r}\text { Total } \\
\mathrm{N} \\
\end{array}$ & & Carbonates & & NOM & & $\mathrm{C} / \mathrm{N}$ & & EC & $\begin{array}{l}\mathrm{pH} \text { in } \\
\mathrm{W}\end{array}$ & $\begin{array}{l}\mathrm{pH} \text { in } \\
\mathrm{KCl}\end{array}$ \\
\hline A & 5,02 & $\mathrm{~L}$ & 0,26 & $\mathrm{~L}$ & 1,16 & $\mathrm{H}$ & 0,13 & $\mathrm{~L}$ & 148,20 & $\mathrm{H}$ & 0,13 & $\mathrm{~L}$ & 42,63 & $\mathrm{H}$ & 2,54 & $\mathrm{H}$ & 11,46 & $\mathrm{H}$ & 385 & 8,42 & 7,84 \\
\hline B & 5,04 & $\mathrm{~L}$ & 0,27 & $\mathrm{~L}$ & 1,29 & $\mathrm{H}$ & 0,14 & $\mathrm{~L}$ & 82,20 & $\mathrm{H}$ & 0,10 & $\mathrm{~L}$ & 34,54 & $\mathrm{H}$ & 2,44 & $M$ & 14,61 & $\mathrm{H}$ & 294 & 8,6 & 7,92 \\
\hline C & 5,16 & $\mathrm{~L}$ & 0,36 & $\mathrm{~L}$ & 0,96 & $\mathrm{H}$ & 0,17 & $\mathrm{~L}$ & 184,60 & $\mathrm{H}$ & 0,08 & $\mathrm{~L}$ & 35,38 & $\mathrm{H}$ & 2,19 & $M$ & 16,00 & $\mathrm{H}$ & 449 & 8,7 & 7,95 \\
\hline D & 5,03 & $\mathrm{~L}$ & 0,27 & L & 0,98 & $\mathrm{H}$ & 0,11 & L & 121,80 & $\mathrm{H}$ & 0,10 & $\mathrm{~L}$ & 35,09 & $\mathrm{H}$ & 2,51 & $\mathrm{H}$ & 14,98 & $\mathrm{H}$ & 295 & 8,68 & 7,91 \\
\hline
\end{tabular}




\section{Table $\mathbf{3}$ (on next page)}

Irrigation water analysis. 


\begin{tabular}{|c|c|c|c|}
\hline Parameter & $\begin{array}{r}\text { Valu } \\
\mathrm{e}\end{array}$ & Units & Method \\
\hline Alkalinity & 194 & $\mathrm{mg} \mathrm{CaCO} 3 / \mathrm{I}$ & PNT-MA/20 \\
\hline Bicarbonates & 191 & $\mathrm{mg} / \mathrm{l}$ & PNT-MA/20 \\
\hline Dissolved calcium & 153 & $\mathrm{mg} / \mathrm{l}$ & PNT-MA/27 \\
\hline Carbonates & $<13$ & $\mathrm{mg} / \mathrm{l}$ & PNT-MA/20 \\
\hline Riverside classification & $\begin{array}{r}\text { C3- } \\
\text { S1 }\end{array}$ & & Calculation \\
\hline Chloride & 136 & $\mathrm{mg} / \mathrm{l}$ & $\mathrm{SM} 4500 \mathrm{Cl} \mathrm{B}(\mathrm{Ed} 22)$ \\
\hline Conductivity (20ㄷ) & 1259 & $\mu S / \mathrm{cm}$ & SM 2510 B (Ed. 22) \\
\hline Hardness & 527 & $\mathrm{mg} \mathrm{CaCO} / \mathrm{I}$ & PNT-MA/27 \\
\hline Phosphate & $<0,92$ & $\mathrm{mg} / \mathrm{l}$ & PNT-MA/04 \\
\hline Dissolved magnesium & 35,1 & $\mathrm{mg} / \mathrm{l}$ & PNT-MA/27 \\
\hline Nitrate & 13,4 & $\mathrm{mg} / \mathrm{l} \mathrm{NO} 3$ & PNT-MA/22 \\
\hline $\mathrm{pH}$ & 8,23 & ud. $\mathrm{pH}$ & SM $4500 \mathrm{H}+\mathrm{B}$ (ed. 22) \\
\hline Dissolved potassium & 4,18 & $\mathrm{mg} / \mathrm{l}$ & PNT-MA/27 \\
\hline SAR & 1,68 & & PNT-MA/88 \\
\hline Adjusted SAR & 3,87 & & PNT-MA/88 \\
\hline Dissolved sodium & 88,6 & $\mathrm{mg} / \mathrm{l}$ & PNT-MA/27 \\
\hline Total sodium in suspension & 11,47 & $\mathrm{mg} / \mathrm{l}$ & UNE-EN 872:2006 \\
\hline Turbidity & 12,6 & NTU & SM 2130 B (Ed. 22) \\
\hline
\end{tabular}

1

2 


\section{Table 4 (on next page)}

Slurry chemical analysis.

Symbols and units are EC, electrical conductivity (mS); OM, organic matter (\%); OOM, oxide organic matter (\%); 


\begin{tabular}{lrrrrrrrrr}
\hline Slurry / Parameter & $\mathrm{pH}$ & $\mathrm{EC}$ & $\mathrm{OM}(\%)$ & $\mathrm{OOM}(\%$ & $\mathrm{Ash}(\%$ & $\% \mathrm{~K}_{2} \mathrm{O}(\mathrm{p} / \mathrm{V})$ & $\% \mathrm{P}_{2} \mathrm{O}_{5}(\mathrm{p} / \mathrm{V})$ & Total N (\%) & $\begin{array}{r}\text { Protei } \\
\text { ) }\end{array}$ \\
\hline Urtica slurry & 7,9 & 1,36 & 0,001 & 0,5 & 0,07 & 0,015 & 0,0019 & 0,005 & 0,027 \\
& 2 & 2 & & & & & & & \\
Equisetum slurry & 7,6 & 1,23 & 0,007 & 0,64 & 0,095 & 0,013 & 0,0024 & 0,002 & 0,015 \\
& 6 & 3 & & & & & & & \\
\hline
\end{tabular}

1 


\section{Table 5 (on next page)}

Average yield achieved in each treatment $(\mathrm{kg} / \mathrm{m})$.

$\mathrm{RD}$, recommended dosage; N, number of repetitions; se, standard error; HSD, post hocTukey test Honestly Significant Difference; Analysis of variance values: Df $=102$; F-value $=0.5079$; p-value $=0.7697 ; \mathrm{HSD}=0.6554$. 


\begin{tabular}{llllll}
\hline & \multicolumn{1}{c}{ Treatments } & N & mean & se & HSD \\
\hline A & Urtica slurry 1 RD & 18 & 2,16 & 0,1525 & a \\
B & Urtica slurry 1/2 RD & 18 & 2,33 & 0,1482 & a \\
C & Urtica slurry 2 RD & 18 & 2,27 & 0,1292 & a \\
D & Urtica + Equisetum slurry & 18 & 2,29 & 0,1377 & a \\
E & Conventional foliar manure & 18 & 2,05 & 0,1583 & a \\
F & Control & 18 & 2,35 & 0,2163 & a \\
\hline
\end{tabular}

1 


\section{Table 6(on next page)}

Average yield achieved in each block pair $(\mathrm{kg} / \mathrm{m})$.

N, number of repetitions; se, standard error; HSD, post hocTukey test Honestly Significant Difference; Analysis of variance values: $\mathrm{Df}=105 ; \mathrm{F}$-value $=8.3942 ; \mathrm{p}$-value $=0.0004 ; \mathrm{HSD}$ $=0.3514$. 


\begin{tabular}{llrll}
\hline Block.pair & N & mean & se & HSD \\
\hline $1-2$ & 36 & 1,97 & 0,0818 & $\mathrm{~b}$ \\
$3-4$ & 36 & 2,18 & 0,1060 & $\mathrm{~b}$ \\
$5-6$ & 36 & 2,57 & 0,1218 & $\mathrm{a}$ \\
\hline
\end{tabular}

1 


\section{Table 7 (on next page)}

Mean and standard error of the size and growth variables for each treatment.

Variables and units are, Height_T1, plant height in $\mathrm{cm}$ at time 1; LeavesN_T1, number of leaves at time 1; LeavesL_T1, leaf length in $\mathrm{cm}$ at time 1; the same for $\mathrm{T} 2$ and $\mathrm{T} 3$;

Flowers $N_{-} T 2$, number of flowers at time 2; AerBiom, aerial biomass in $\mathrm{kg}$ in each meter of the ridge. 


\begin{tabular}{|c|c|c|c|c|c|c|c|c|c|c|c|c|c|}
\hline \multirow{2}{*}{$\begin{array}{l}\text { Treatments } \\
\text { / } \\
\text { Variables }\end{array}$} & \multirow[b]{2}{*}{$\mathbf{N}$} & \multicolumn{2}{|c|}{ A } & \multicolumn{2}{|c|}{ B } & \multicolumn{2}{|c|}{ C } & \multicolumn{2}{|c|}{ D } & \multicolumn{2}{|c|}{$E$} & \multicolumn{2}{|c|}{$\mathbf{F}$} \\
\hline & & mean & se & mean & se & mean & se & mean & se & mean & se & mean & se \\
\hline Height_T1 & 30 & 18,30 & 0,9105 & 19,13 & 0,6748 & 16,67 & 0,9288 & 18,00 & 0,6794 & 18,17 & 0,9937 & 16,20 & 0,7271 \\
\hline Height_T2 & 30 & 51,63 & 1,2360 & 53,73 & 1,6305 & 57,97 & 1,1840 & 57,50 & 0,8699 & 48,73 & 2,2899 & 55,87 & 1,9604 \\
\hline Height_T3 & 30 & 60,93 & 1,9350 & 63,63 & 2,0512 & 67,27 & 2,0232 & 65,57 & 1,4466 & 57,07 & 2,0396 & 60,13 & 2,4919 \\
\hline LeavesN_T1 & 30 & 10,77 & 0,5237 & 13,17 & 0,5081 & 11,73 & 0,5393 & 13,17 & 0,5153 & 12,37 & 0,6439 & 13,40 & 0,6138 \\
\hline LeavesN_T2 & 30 & 13,67 & 0,3269 & 15,73 & 0,3811 & 14,23 & 0,3225 & 15,30 & 0,4836 & 15,43 & 0,4062 & 15,70 & 0,4632 \\
\hline LeavesN_T3 & 30 & 14,60 & 0,3876 & 17,17 & 0,6977 & 17,30 & 0,6149 & 16,83 & 0,7344 & 17,23 & 0,7293 & 16,73 & 0,6616 \\
\hline LeavesL_T1 & 30 & 19,90 & 0,8475 & 21,93 & 0,6341 & 16,27 & 0,7027 & 18,90 & 0,8863 & 19,40 & 0,9416 & 16,40 & 1,0044 \\
\hline LeavesL_T2 & 30 & 28,23 & 0,4154 & 28,47 & 0,4450 & 29,30 & 1,0397 & 27,87 & 0,7486 & 28,10 & 0,6176 & 29,93 & 0,8549 \\
\hline LeavesL_T3 & 30 & 31,50 & 0,5427 & 34,03 & 0,5384 & 33,53 & 0,5571 & 32,93 & 0,7142 & 32,13 & 0,7095 & 32,33 & 0,7133 \\
\hline FlowersN_T2 & 30 & 13,17 & 1,4676 & 20,23 & 0,7435 & 19,73 & 0,8495 & 18,70 & 0,9565 & 20,57 & 1,4575 & 16,80 & 1,2179 \\
\hline AerBiom & 18 & 1,56 & 0,0353 & 1,70 & 0,1695 & 1,82 & 0,2016 & 1,62 & 0,1264 & 1,54 & 0,1442 & 1,71 & 0,1219 \\
\hline
\end{tabular}

1 


\section{Table 8(on next page)}

ANOVA and post hoc Tukey test performed with the residuals of the Block Pair.

p, p-value for ANOVA (* means significant differences); KW-p, Kruskal-Wallis p-value, was only calculated when residuals did not fit normal distribution (* means significant differences); HSD,post hocTukey test Honestly Significant Difference; eta ${ }^{2}$, eta-squared statistics for the effect size in ANOVA, was only calculated when there were significant differences (* means small effect sizes); levene, levene $p$-value for variance verification, was only calculated when there were significant differences (* means non homogeneous standard deviations); shap, W of Shapiro-Wilk test of residuals (* means data did not fit normal distribution). 


\begin{tabular}{|c|c|c|c|c|c|c|c|c|c|c|c|c|}
\hline $\begin{array}{c}\text { Size and } \\
\text { growth } \\
\text { variables }\end{array}$ & $\mathbf{p}$ & $K W-p$ & HSD & eta2 & levene & shap & A_hsd & B_hsd & C_hsd & D_hsd & E_hsd & F_hsd \\
\hline Height_T1 & 0,12486 & NA & 3,3791 & NA & NA & 0,0782 & a & a & a & a & a & a \\
\hline Height_T2 & $0,0002^{*}$ & $0,0029 *$ & 6,5359 & 0,1260 & $0,000 *$ & $0,027^{*}$ & $a b$ & $a b$ & a & a & $b$ & a \\
\hline Height_T3 & $0,0051^{*}$ & NA & 8,2365 & $0,091^{*}$ & 0,1708 & 0,7665 & $a b$ & $a b$ & a & a & $b$ & $a b$ \\
\hline LeavesN_T1 & $0,0062^{*}$ & NA & 2,2813 & $0,088^{*}$ & 0,6005 & 0,0716 & $b$ & a & $a b$ & a & $a b$ & a \\
\hline LeavesN_T2 & $0,0006^{*}$ & NA & 1,6383 & 0,1155 & 0,1090 & 0,8955 & $b$ & a & $a b$ & $a b$ & a & a \\
\hline LeavesN_T3 & $0,0320^{*}$ & 0,0339* & 2,6433 & $0,067^{*}$ & 0,0660 & $0,004 *$ & $b$ & $a b$ & a & $a b$ & $a b$ & $a b$ \\
\hline LeavesL_T1 & $0,00001^{*}$ & NA & 3,4482 & 0,1591 & 0,0474 & 0,3701 & a & a & $b$ & $a b$ & $a b$ & $b$ \\
\hline LeavesL_T2 & 0,29874 & NA & 2,9408 & NA & NA & 0,5030 & a & a & a & a & a & a \\
\hline LeavesL_T3 & 0,05747 & NA & 2,5866 & NA & NA & 0,7173 & a & a & a & a & a & a \\
\hline FlowersN_T2 & $0,00004^{*}$ & NA & 4,6913 & 0,1467 & $0,004 *$ & 0,0852 & $b$ & a & a & a & $\mathrm{a}$ & $a b$ \\
\hline AerBiom & 0.73962 & NA & 0,5863 & NA & NA & 0,0012 & a & a & a & a & $\mathrm{a}$ & a \\
\hline
\end{tabular}
1 


\section{Table 9 (on next page)}

Chlorophyll A, B and total Chlorophyll content by treatment.

A recommended Urtica dose; $B$ half the recommended dose; $C$ double the recommended dose; D Urtica recommended dose in combination with Equisetum; E conventional foliar manure; F control; A_Chlor, A chlorophyll; B_Chlor, B chlorophyll; Total_Chlor_1, total chlorophyll 1; Total_Chlor_2, total chlorophyll 2; Unit is chlorophyll mg per $\mathrm{g}$ of fresh plant; $\mathrm{N}$, number of repetitions; se, standard error; HSD, post hocTukey test Honestly Significant Difference; ANOVA values are in A_Chlor $p$-value $=0.35$; $\mathrm{HSD}=0.18$; $\mathrm{B}_{-}$Chlor $\mathrm{p}$-value $=0.46$; $\mathrm{HSD}=0.08 ;$ Total_Chlor_1 p-value $=0.48 ; \mathrm{HSD}=0.09$; Total_Chlor_2 $\mathrm{p}$-value $=0.32 ; \mathrm{HSD}=$ 0.26 . 


\begin{tabular}{|c|c|c|c|c|c|c|c|c|c|c|c|c|c|c|c|c|c|c|c|}
\hline \multirow{2}{*}{$\begin{array}{c}\text { Chlorophyll } \\
\text { variables }\end{array}$} & \multirow{2}{*}{$\mathrm{n}$} & \multicolumn{2}{|c|}{ A } & \multicolumn{2}{|c|}{ B } & \multicolumn{2}{|c|}{ C } & \multicolumn{2}{|c|}{$\mathrm{D}$} & \multicolumn{2}{|c|}{$E$} & \multicolumn{2}{|c|}{$\mathrm{F}$} & \multicolumn{6}{|c|}{ HSD } \\
\hline & & mean & se & mean & se & mean & se & mean & se & mean & se & mean & se & $A$ & B & C & D & $E$ & $\mathrm{~F}$ \\
\hline A_Chlor & 108 & 0,52 & 0,04 & 0,54 & 0,04 & 0,61 & 0,05 & 0,63 & 0,03 & 0,51 & 0,03 & 0,57 & 0,05 & a & a & a & a & a & a \\
\hline B_Chlor & 108 & 0,14 & 0,02 & 0,17 & 0,02 & 0,18 & 0,02 & 0,16 & 0,01 & 0,14 & 0,01 & 0,16 & 0,02 & a & a & a & $a$ & $a$ & a \\
\hline Total_Chlor_1 & 108 & 0,19 & 0,02 & 0,21 & 0,02 & 0,23 & 0,03 & 0,21 & 0,02 & 0,18 & 0,01 & 0,21 & 0,02 & $a$ & a & a & $a$ & a & a \\
\hline Total_Chlor_2 & 108 & 0,67 & 0,06 & 0,71 & 0,06 & 0,82 & 0,08 & 0,80 & 0,04 & 0,65 & 0,04 & 0,73 & 0,07 & a & a & a & a & a & a \\
\hline
\end{tabular}


Figure 1 (on next page)

Experimental design

Treatments are noted as A, Urtica slurry Recommended Dose (RD); B, Urtica slurry 1/2 RD; C, Urtica slurry 2XRD; D, Urtica + Equisetum slurry; $\mathrm{E}$, Conventional foliar manure; $\mathrm{F}$, Control treatment. Blocks are noted as B1, B2, B3, B4, B5, and B6. 
Blocks 1-2 (15 m)

Blocks 3-4 $(15 \mathrm{~m})$

12 ridge

Ridge 1

Ridge 2

Ridge 3

Ridge 4

Ridge 5

Ridge 6

Ridge 7

Ridge 8

Ridge 9

Ridge 10

Ridge 11

Ridge 12

\section{$3 m$}

Position

edge

1

$5 \mathrm{~m}$

2

$5 \mathrm{~m}$

3

m)

\begin{tabular}{|c|c|c|c|c|c|c|c|c|c|}
\hline Position & 1 & 2 & 3 & 4 & 5 & 6 & 7 & 8 & 9 \\
\hline edge & & & & & & & & & \\
\hline & D & $\mathrm{F}$ & C & $B$ & $E$ & A & D & $\mathrm{F}$ & $E$ \\
\hline & & B1 & & & B3 & & & B5 & \\
\hline & B & $E$ & A & C & $F$ & D & C & A & B \\
\hline & & & & & & & & & \\
\hline & C & B & $\mathrm{F}$ & D & $A$ & $E$ & $B$ & C & D \\
\hline & & B2 & & & B4 & & & B6 & \\
\hline & $E$ & $A$ & D & $\mathrm{F}$ & $B$ & C & $A$ & $E$ & $\mathrm{~F}$ \\
\hline & & & & & & & & & \\
\hline
\end{tabular}

4

5

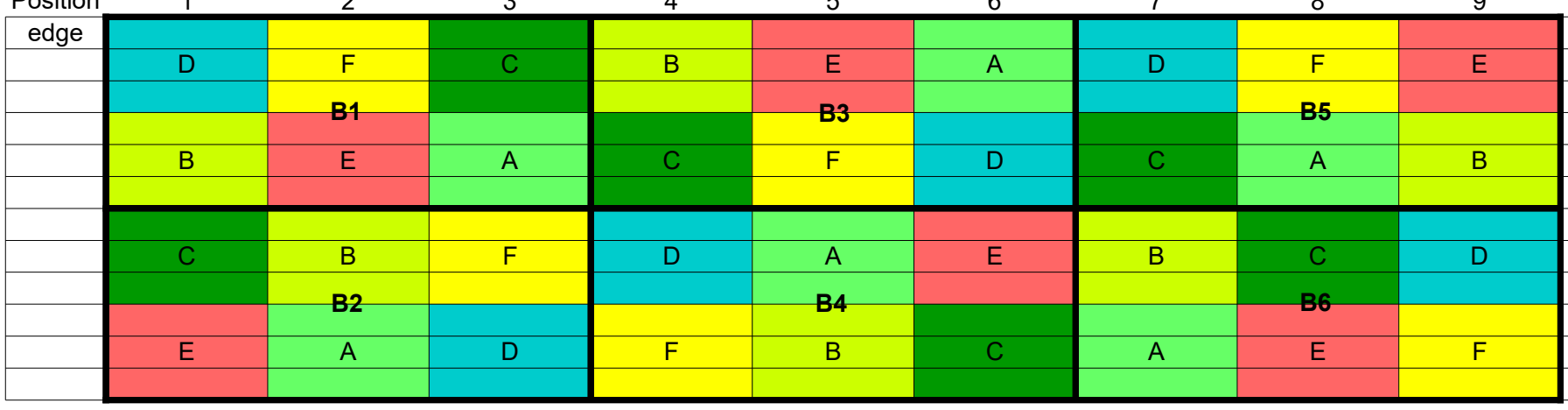

Blocks 5-6 (15 m)

$3 m$ edge .

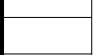

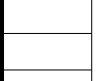
\begin{tabular}{|l|}
\hline \\
\hline \\
\hline \\
\hline
\end{tabular} Water inlet to the plot 
Figure 2

Effect of treatments on yield $(\mathrm{kg} / \mathrm{m})$ with all the data (102 degrees of freedom).

Treatments are noted as A, Urtica slurry RD; B, Urtica slurry 1/2 RD; C, Urtica slurry 2 RD; D, Urtica + Equisetum slurry; E, Conventional foliar manure; F, Control treatment. HSD, Honestly Significant Difference $=0.6554 \mathrm{~kg} / \mathrm{m}$. Boxes show the 25 th and 75 th percentiles . Lines in the boxes show the median values.

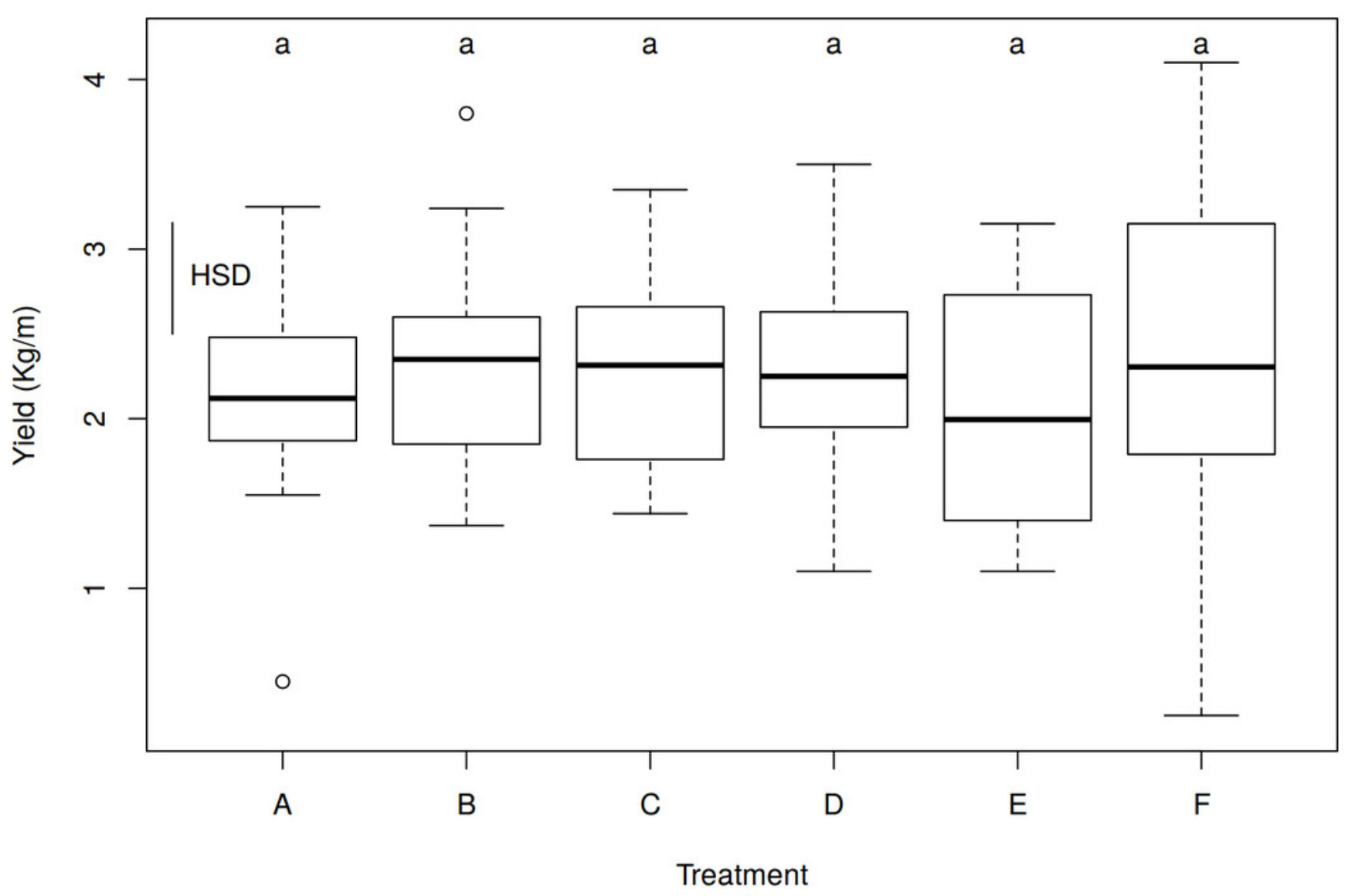


Figure 3

Effect of watering by block pairs on yield $(\mathrm{kg} / \mathrm{m})$.

HSD, Honestly Significant Difference $=0.3514 \mathrm{~kg} / \mathrm{m}$. Boxes show the 25 th and 75 th percentiles. Lines in the boxes show the median values.

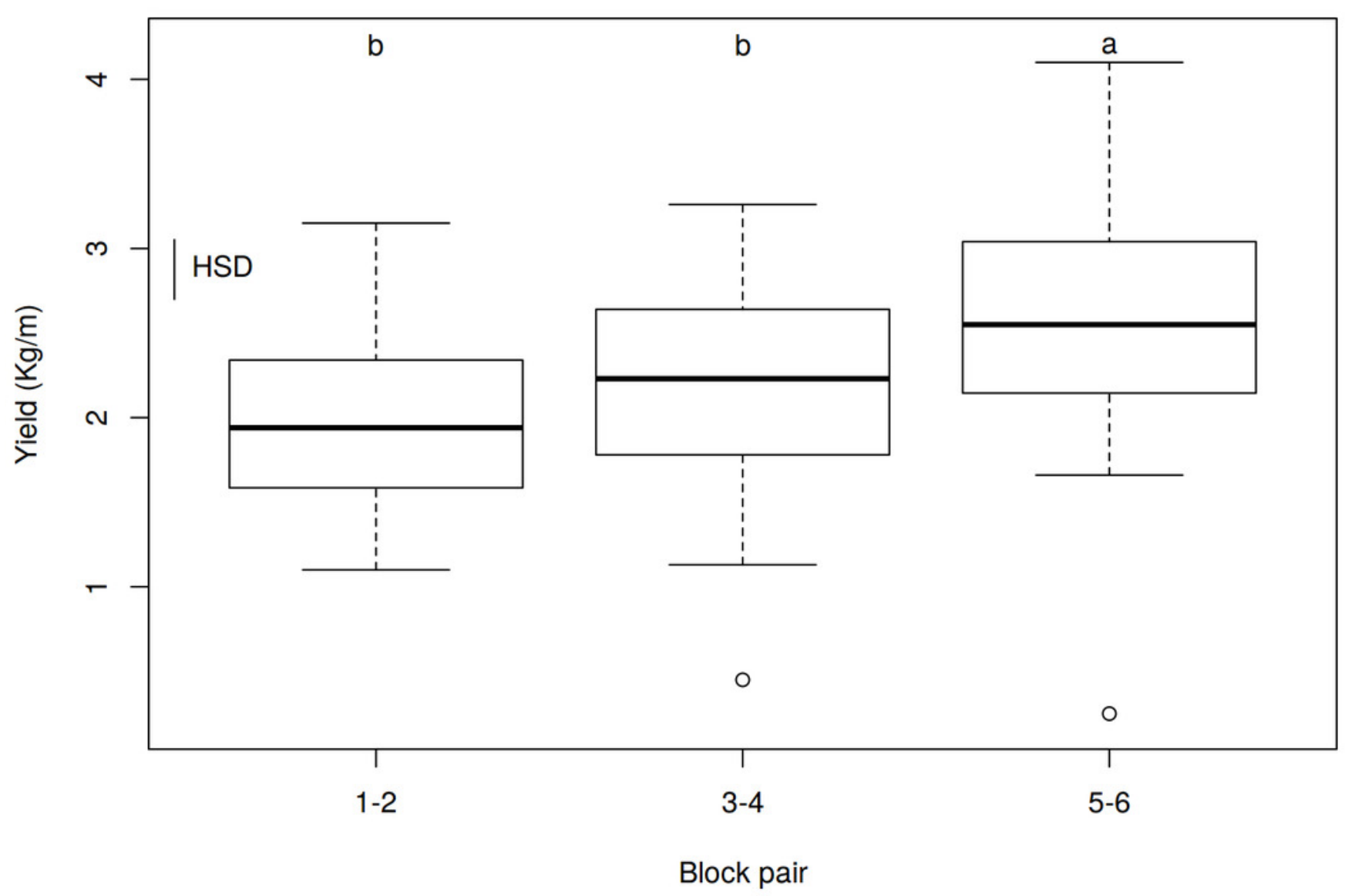


Figure 4

Effect of treatments on yield $(\mathrm{kg} / \mathrm{m})$ with the residuals of the Block Pair ANOVAs.

Boxes show the 25th and 75th percentiles. Lines in the boxes show the median values. Df, degrees of freedom $=102 ;$ F-value $=0.5914 ;$-value $=0.7065 ; \mathrm{HSD}$, Honestly Significant Difference $=0.6073 \mathrm{~kg} / \mathrm{m}$.

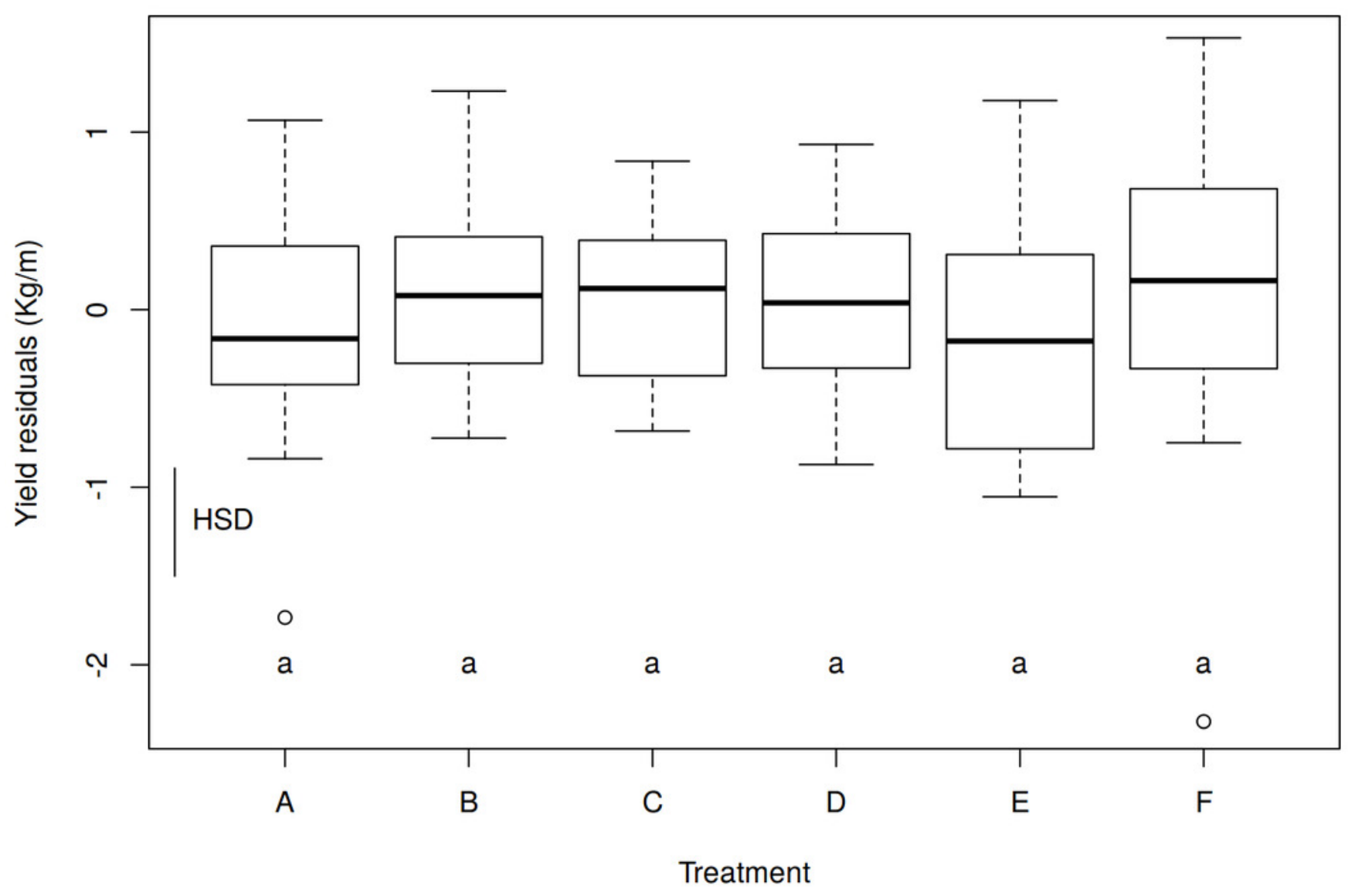


Figure $\mathbf{5}$ (on next page)

Mean yield values for treatments and block pairs.

Colors represent treatments. The columns with the same letter represent values that are not significantly different at the 0.05 level of probability according to the HSD test. Error bars correspond to standard error. Treatments are noted as A: recommended Urtica dose; B: half the recommended dose; C: double the recommended dose; D: Urtica recommended dose in combination with Equisetum; E: Conventional foliar manure; F: control. 


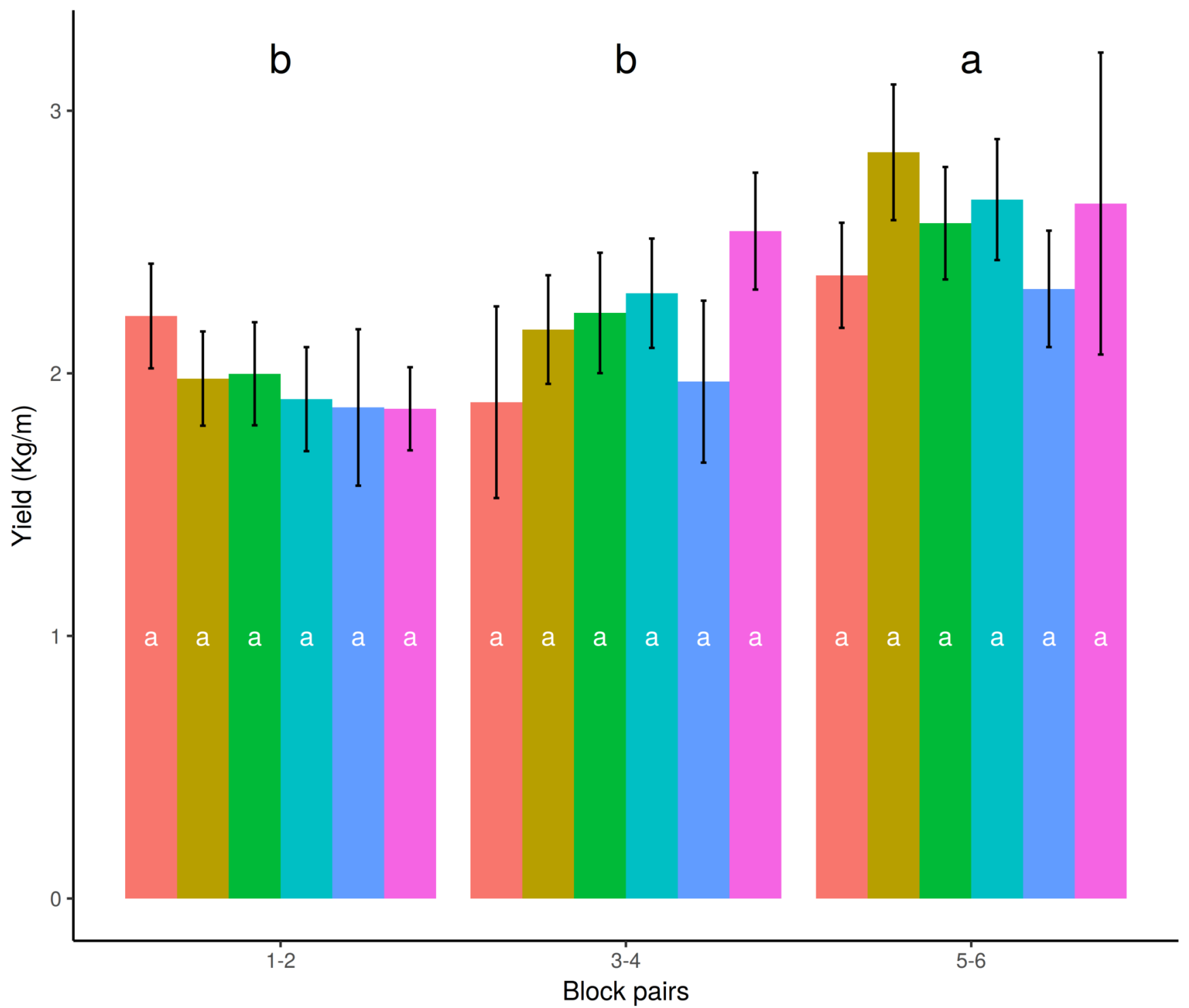

Treatment

A
B
C
D
E
F


Figure 6 (on next page)

Effect of treatments on the plant size variables at times 1, 2 and 3.

A Height; B Number of leaves; C Leaves length; Colors and symbols represent treatments. Dates (m/d) of each time were T1: 4/14; T2: 5/3; T3: 6/1. Treatments are noted as $U$ slurry 1 RD: recommended Urtica dose; U slurry 1/2 RD: half the recommended dose; U slurry 2 RD: double the recommended dose; $U$ + E slurry: Urtica recommended dose in combination with Equisetum; Conventional : conventional foliar manure; control. 
Figure 7 (on next page)

Mosaic plot for the presence of Leptinotarsa decemlineata for different times, treatments and watering regimes.

Time dates (m/d) were T1: 4/14; T2: 5/3; T3: 6/1. Treatments are noted as A: recommended Urtica dose; B: half the recommended dose; $\mathrm{C}$ : double the recommended dose; D: Urtica recommended dose in combination with Equisetum; E: Conventional foliar manure; F: control. Watering regimes were 1: blocks 1 and 2; 2: blocks 3 and 4; 3: blocks 5 and 6 . 


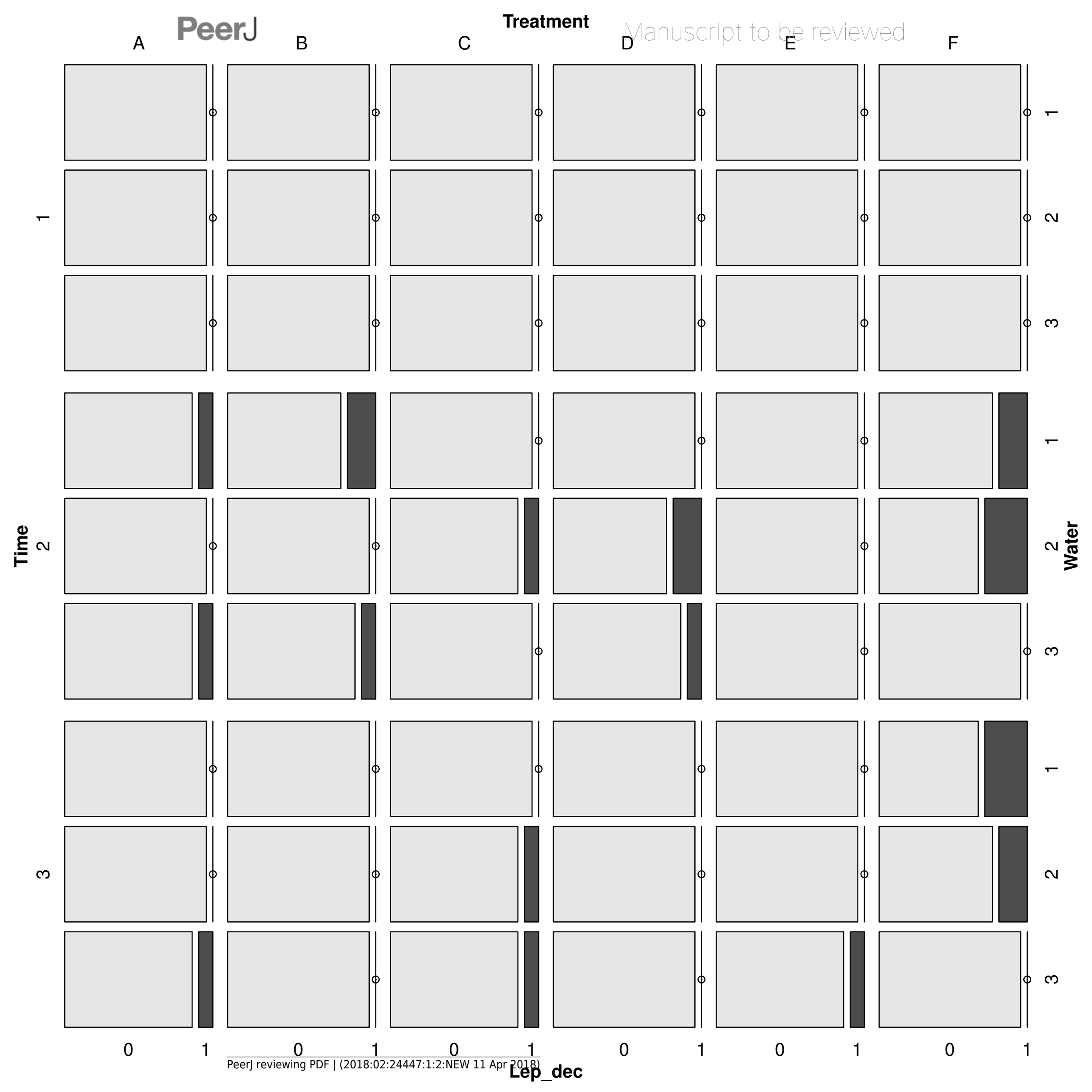




\section{Figure 8 (on next page)}

Mosaic plot for the presence of Phytophthora infestans for different times, treatments and watering regimes.

Time dates (m/d) were $\mathrm{T} 1: 4 / 14 ; \mathrm{T} 2: 5 / 3 ; \mathrm{T3}: 6 / 1$. Treatments are noted as A: recommended Urtica dose; B: half the recommended dose; $\mathrm{C}$ : double the recommended dose; D: Urtica recommended dose in combination with Equisetum; E: Conventional foliar manure; F: control. Watering regimes were 1: blocks 1 and 2; 2: blocks 3 and 4; 3: blocks 5 and 6 . 
